\title{
A Study on the Factors Affecting the Intention to Payment Service Using Biometrics
}

\author{
Soo Yeop $\mathrm{Kim}^{1}$, Seok Hee $\mathrm{Lee}^{2}$, Yong Duk $\mathrm{Chi}^{3}$, Eun Tack $\mathrm{Im}^{4}$ and \\ Gwang Yong Gim ${ }^{5}$ \\ ${ }^{1,2,3}$ Department of IT Policy Management, Soongsil University, Republic of Korea \\ ${ }^{4,5}$ Department of Business Administration, Soongsil University, Republic of Korea \\ ${ }^{1}$ sooyeopkim@hotmail.com, ${ }^{2}$ chris@lghitachi.co.kr, ${ }^{3}$ ofcyd@daum.net, \\ ${ }^{4}$ iet030507@gmail.com, ${ }^{5}$ gygim@ssu.ac.kr
}

\begin{abstract}
As personal customized service is accelerating and system networked is spreading, the methods of user authentication have developed. However, even though biometric technology is an innovative technology of user authentication, this field has a lack of systematic studies or researches considerably Therefore, this study conducted an empirical study on influential factors in intention to use of biometric authentication focusing on financial payment service. 18 hypotheses were verified, only four hypotheses were rejected. First of all, transaction convenience, perceived security, and perceived compatibility had a positive effect on performance expectancy and effort expectancy. Second, benefit convenience had a positive effect on effort expectancy but it did not have an effect on performance expectancy. Third, perceived mobility had a positive effect on performance expectancy but it did not have an effect on effort expectancy. Fourth, personal innovativeness did not have a positive effect on both performance expectancy and effort expectancy. Fifth, performance expectancy, effort expectancy, social influence, Lastly, the experience of biometric authentication usage and regulation effect by ages showed significant result. This study suggested the practical level implications to use biometric authentication payment in the future and discussed the limitation of the study and henceforth future research. $\backslash$
\end{abstract}

Keywords: Biometrics, Unified Theory of Acceptance and Use of Technology, Technology-based self-service, Mobile Payment Service

\section{Introduction}

Lately, non-face-to-face real name confirmation technology has increased significantly as non-face-to-face financial services have received attention due to the activation of pintech industry and the spread of smartphones. The abolition of the use of public certificate duties from 2015, alternative authentication means became necessary, and as non-face-toface real name confirmation is allowed, there is a need for new authentication means, as the financial security has changed from the existing pre-regulation to the post-regulation, the security system of the financial institution has to be established to secure the safety, therefore, the introduction and review of the biometric authentication technology are being actively promoted [12].

This study based on Unified Theory of Acceptance and Use of Technology (UTAUT), the study model was constructed using the characteristics of Technology-based selfservice (TBSS) and the characteristics of biometric authentication service as independent variables. The purpose of this study is to analyze the effect of these characteristics on the performance expectation and effort expectation of the UTAUT model in the use

Received (October 21, 2017), Review Result (January 25, 2018), Accepted (March 12, 2018) 
environment of biometric authentication settlement service as well as the effect on use intention based on this.

\section{Theoretical Background}

\subsection{Biometrics}

Biometrics technology is a technology that extracts and registers a person's unique behavior and physical characteristics into a device for recognition and then identifies or authenticates an individual [16]. The fingerprint with the longest history of biometric technology has been used to prove identity since the ancient Babylonian era. Modern biometric technologies have been introduced in full scale since the first discoveries of fingerprints in 1684 by N. Gruw of the Royal Society of England [19]. In Korea, all finger prints of all people over the age of 17 have been collected and registered on the computer in the 1970s according to the amendment of the resident registration law, and they have been used for financial transactions, public affairs, and criminal investigations. Currently, various techniques such as iris, face, vein, and voice are used in addition to fingerprint. In the field of Internet banking, a method of authentication using face recognition has also been introduced [22].

However, once exposed biometric information cannot be changed, and the biometric information to be substituted is also finite and there is a possibility that the biometric information of the individual is illegally used, so that the resistance to infringement of personal privacy, inconvenience to use the device, and error rate are not 0 (zero)\% is recognized as a disadvantage [19].

\subsection{Technology-Based Self-Service (TBSS)}

Interest in technology-based self-service is increasing as interest in the 4th industrial revolution is getting hotter and the introduction of advanced technology is becoming common in all service industries and the role of technology is recognized as important [15]. The user can conveniently use the service as soon as he or she wishes to use the service without restriction of time and place, and the cost is reduced in comparison with the time and efforts inputted for the use of service.

Using quality of TBSS and interaction with employees through comparison of total emotion models based on customer's expectation-based contribution model in various characteristics such as reliability, ease of use, service pleasure and control, and technology related concepts. However, it can be seen as a great benefit to customers in terms of cost savings from a customer's direct service use perspective, but in some unpredictable situations, customers may not be able to respond immediately, so sometimes a customer complaint arises. Therefore, TBSS was a subject that should be taken very seriously by the company [6].

The ease of use, reliability, and enjoyment have a positive effect on intention to use TBSS [5], and the intention to use TBSS is affected not only by customers but also by attitudes of companies and employees responding to customers [4]. In TBSS, cost savings against customers' time and effort proved to be a variable that has a significant effect on the value that customers feel about services or businesses [1].

The results of research conducted on users of self-scanning technology for TBSS reveal that user's control, hedonic value, and employee response directly affect on customer satisfaction, and this in consequence has an influence on the customers' intention to reuse [21]. 


\subsection{Characteristics of Mobile Payment}

Electronic payment means to pay or settle the price of goods or services using electronic means [15]. In a study of behavioral intentions of mobile banking using technology acceptance models, we found that perceived reliability, perceived selfefficacy, and financial costs added to existing factors have a significant impact on behavioral intent [19].

On the intent of NFC mobile payment acceptance, it is clear that individual's innovation, absorption of services, and alternative attractiveness, [23] and empirical studies for the use and diffusion of mobile credit cards have identified four factors as perceived ease, image, suitability and promotion [13].

According to a study on the opportunity to use smartphone easy payment service, the most important reason was the convenience of service use, followed by events of providing economic benefits, connection with existing services, and curiosity of services [7].

In the study on acceptance factors of mobile payment service, it was confirmed that social influence, personal characteristics and belief in behavior (perceived risk, suitability, perceived cost, and relative advantage) are important determinants of both the introduction and use of mobile payment service [17]. And In the study on introduction of mobile payment service, it was confirmed that social influence, personal characteristics and belief in behavior (perceived risk, suitability, perceived cost, and relative advantage) are important determinants of both introduction and use of mobile payment service [28].

\subsection{Unified Theory of Acceptance and Use of Technology}

In a study of factors influencing intention to use proposed for the first time to improve the limit of not fully taking various variables into consideration in existing TAM and extended TAM, and said that compared to the existing TAM, the explanatory power is increased by about $20 \sim 30 \%$. The Unified Theory of Acceptance and Use of Technology generalized representing models of information technology acceptance such as rational behavior theory (TRA), technology acceptance model, planned action theory (TPB), mixed model of TAM and TPB, PC-use model, innovation diffusion theory, social recognition theory, and Unified Theory of Acceptance and Use of Technology model as in Figure 1 [27].

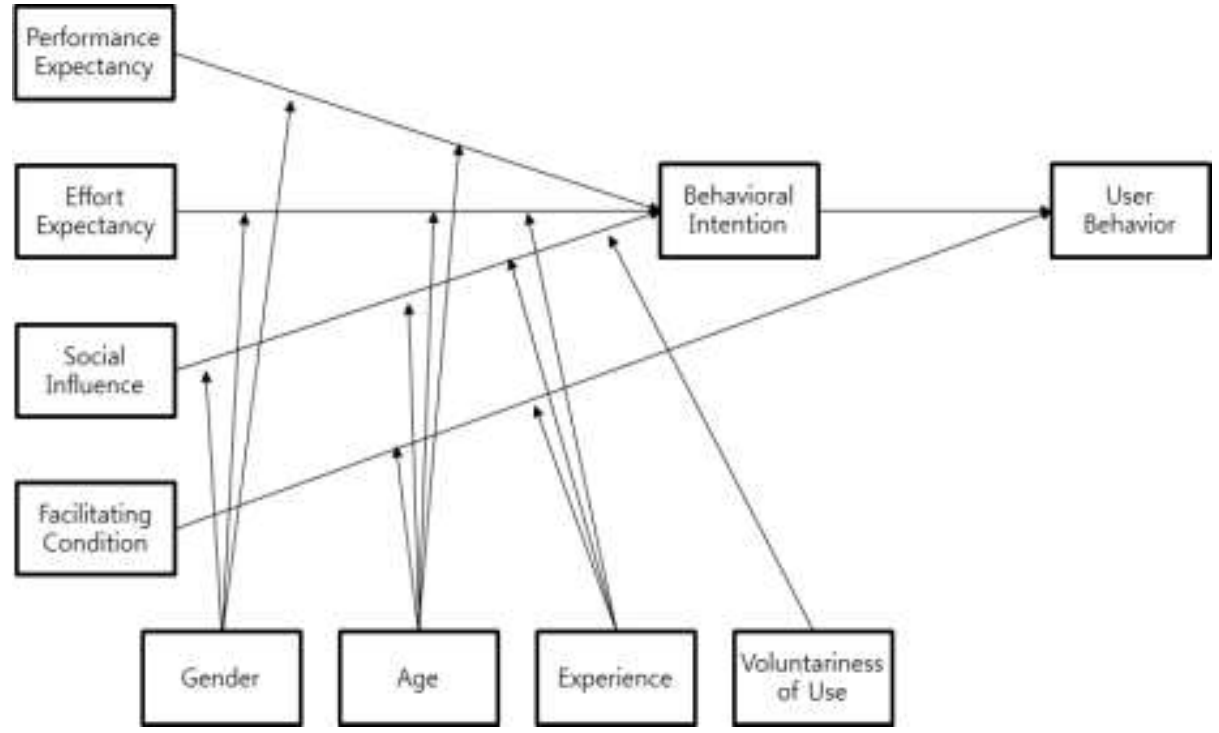

Figure 1. UTAUT Model (Venkatesh et al., 2003) 
Effort expectations mean the degree of ease of use of the system that the user feels is easy to use the system. Social influence means the degree to which a social atmosphere or the recommendation or use for surrounding people around the user to use the new system is justified. The facilitating conditions that directly affect the use behavior are the organizational or technical factors that support the user to use the new system. And it said that the control variable plays its role when the spontaneity of gender, age, experience, and use affect on the result expectation, efforts expectation, social influence and promotional condition in controlling behavioral intention and use behaviors.

\section{Research model and Hypothesis}

\subsection{Research Model}

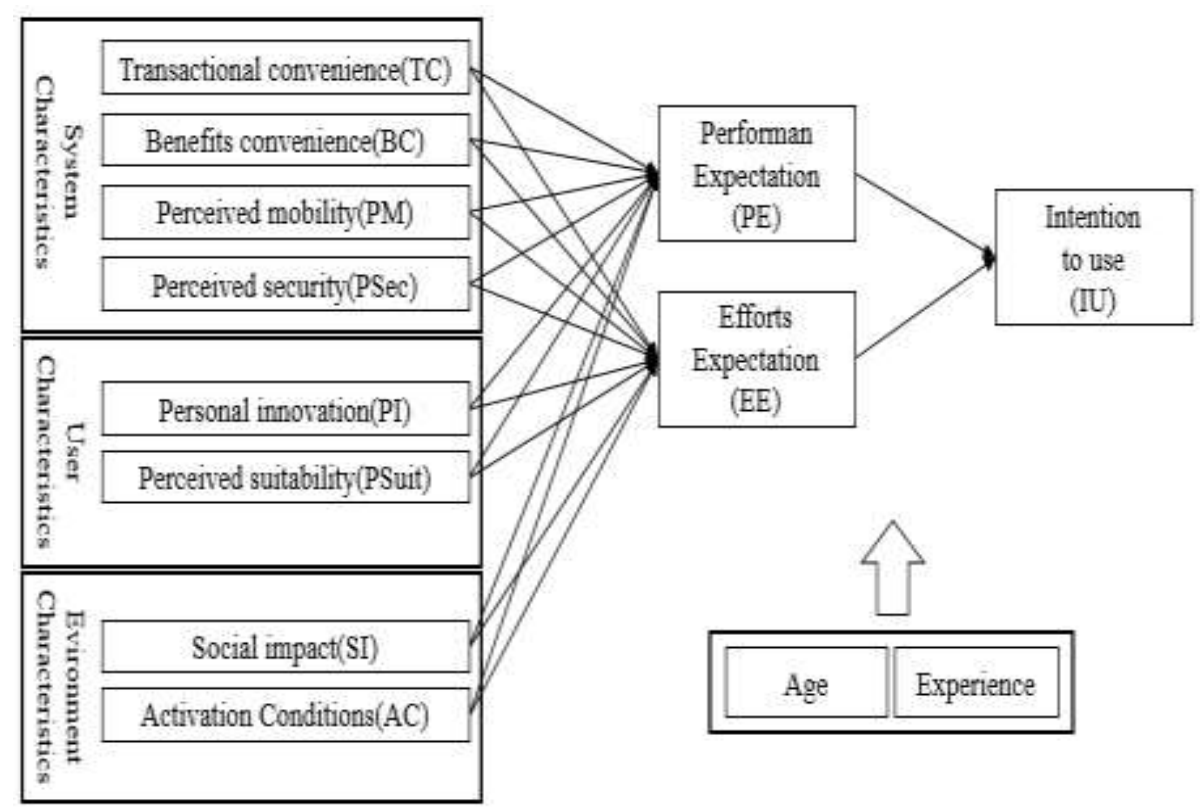

Figure 2. Research Model

\subsection{Hypothesis}

\subsubsection{Hypothesis on the System Characteristics of Biometric Authentication Payment} System

\subsubsection{Convenience, Performance and Expectation of Effort}

H1a: Transactional convenience will have a positive effect $(+)$ on performance expectations.

H1b: Transactional convenience will have a positive effect (+) on efforts expectations.

H2a: Benefits convenience will have a positive effect $(+)$ on performance expectations.

$\mathrm{H} 2 \mathrm{~b}$ : Benefits convenience will have a positive effect (+) on efforts expectations.

\subsubsection{Perceived Mobility, Performance and Effort Expectations}

H3a: Perceived mobility will have a positive effect $(+)$ on performance expectations.

H3b: Perceived mobility will have a positive effect $(+)$ on efforts expectations. 


\subsubsection{Perceived Security, Performance and Effort Expectations}

H4a: Perceived security will have a positive effect (+) on performance expectations.

H4b: Perceived security will have a positive effect (+) on efforts expectations.

\subsubsection{Hypothesis on the User Characteristics of Biometric Authentication Payment} System

\subsubsection{Perceived Suitability, Performance and Effort Expectations}

H5a: Perceived suitability will have a positive effect $(+)$ on performance expectations.

H5b: Perceived suitability will have a positive effect $(+)$ on efforts expectations.

\subsubsection{Personal Innovation, Performance and Efforts Expectation}

H6a: Personal innovativeness will have a positive effect $(+)$ on performance expectations.

H6b: Personal innovativeness will have a positive effect $(+)$ on efforts expectations.

\subsubsection{Hypothesis on Performance and Efforts Expectations and Intention to Use}

H7: Performance expectation will have a positive effect (+) on intention to use.

H8: Efforts expectation will have a positive effect $(+)$ on intention to use.

\subsubsection{Hypothesis on the Environmental Characteristics of Biometric Authentication Payment}

\subsubsection{Social Impact and Intention to Use}

H9: Social impact will have a positive effect $(+)$ on intention to use.

\subsubsection{Activation Conditions and Intention to Use}

H10: Activation condition will have a positive effect (+) on intention to use.

\section{Empirical Analysis}

\subsection{Characteristics of the Sample}

According to the characteristics of the respondents, the percentage of males are high with $244(74.4 \%)$ of males and $84(25.6 \%)$ of females, the age group of the 30s was the highest with $33.2 \%$ (109), followed by the $40 \mathrm{~s}$ and $20 \mathrm{~s}$. The ratio of college graduates was highest at $58.2 \%$ (191), followed by graduate students (16.4\%).

And the ratio of occupation was highest in office/technical work with 135 (41.2\%), followed by specialized job with 52 (15.9\%), except for college and high school students.

$253(77.1 \%)$ have experienced the use of biometric authentication, but $112(44.3 \%)$ of them have used biometric authentication services.

It stays at a fairly low level with $34.1 \%$ of the total 328 respondents. And, the use of biometric authentication shows that $71.3 \%$ of the fingerprint is used and $57.3 \%$ of the smartphone is used as the place of use, meaning it is still an initial entry stage.

\subsection{Exploratory Factor Analysis}

Exploratory factor analysis (EFA) was used to identify the inter-factor structure by exploring the degree to which the intrinsic factors of observation variables were connected. Factor analysis was performed by setting the criterion of factor eigenvalue to 
1.0 using the Principal Component Analysis and Varimax quadrature rotation method. In case of factor loading, it was judged to be significant only at 0.5 or more [18], and all the questions were extracted as 11 components according to original intention.

Reliability analysis was performed by verifying the internal validity of the extracted components was shown to be greater than 0.7 in all Cronbach's Alpha coefficients of the measured variables, securing the reliability.

Table 1. Cronbach's Alpha

\begin{tabular}{|c|l|}
\hline Transactional convenience(TC) & 0.857 \\
\hline Personal innovation(PI) & 0.915 \\
\hline Social impact(SI) & 0.934 \\
\hline Perceived security(PSec) & 0.925 \\
\hline Activation Conditions(AC) & 0.874 \\
\hline Efforts expectation(EE) & 0.883 \\
\hline Perceived mobility(PM) & 0.812 \\
\hline Intention to use(IU) & 0.937 \\
\hline Perceived suitability(PSuit) & 0.842 \\
\hline Benefits convenience(BC) & 0.894 \\
\hline Performance expectation(PE) & 0.920 \\
\hline
\end{tabular}

\subsection{Confirmatory Factor Analysis}

Confirmatory Factor Analysis (CFA) was conducted using AMOS for the measured variables extracted by exploratory factor analysis. In contrast to the exploratory factor analysis, which is not yet established theoretically or is lacking in systematization, the confirmatory factor analysis is based on the theoretical background, and is the method to execute factor analysis by setting the relationship of variables [14].

Absolute fit index, Incremental fit index, Parsimonious fit index and other indices are used to determine the fit of the research model. The absolute fit index is used to evaluate the overall fit of the model, the incremental fit index is compared with the base model to assess how much the proposed model has improved, and the Parsimonious fit index is used to evaluate the model simplicity.

It was measured to be X2 $=1115.149(\mathrm{p}=0.000), \mathrm{x} 2 / \mathrm{df}=1.950, \mathrm{RMSEA}=0.051$, GFI $=0.858, \mathrm{AGFI}=0.826, \mathrm{NFI}=0.913, \mathrm{CFI}=0.955, \mathrm{PNFI}=0.784$ and $\mathrm{GFI}=0.871$. All the indices are shown to be satisfactory by showing the level of satisfaction with the standard, so it can be judged as a generally suitable research model $[9,25,26]$.

Table 2. Model Suitability of Confirmatory Factor Analysis

\begin{tabular}{|c|c|c|c|c|c|c|}
\hline $\mathrm{x}^{2}(\mathrm{p})$ & $\mathrm{x}^{2} / \mathrm{df}$ & RMSEA & GFI & AGFI & NFI & CFI \\
\hline $\mathrm{P} \leqq 0.05 \sim 0.1$ & $1.0 \leqq \mathrm{x}^{2} / \mathrm{df} \leqq 3.0$ & $\leqq 0.05 \sim 0.08$ & $\geqq 0.8 \sim 0.9$ & $\geqq 0.8 \sim 0.9$ & $\geqq 0.8 \sim 0.9$ & $\geqq 0.8 \sim 0.9$ \\
\hline $\begin{array}{c}935.021 \\
(\mathrm{p}=0.000)\end{array}$ & 1.758 & 0.045 & 0.878 & 0.847 & 0.926 & 0.967 \\
\hline
\end{tabular}

Table 3. Concept Reliability Analysis of Confirmatory Factor Analysis

\begin{tabular}{|c|c|c|c|c|c|c|c|c|c|c|c|}
\hline & TC & BC & PM & PSec & PI & PSuit & PE & EE & SI & AC & IU \\
\hline CR & 0.904 & 0.903 & 0.829 & 0.941 & 0.859 & 0.883 & 0.890 & 0.927 & 0.920 & 0.855 & 0.938 \\
\hline AVE & 0.759 & 0.701 & 0.620 & 0.842 & 0.670 & 0.718 & 0.730 & 0.808 & 0.741 & 0.598 & 0.834 \\
\hline
\end{tabular}

Discriminant validity exists if the correlation coefficient between latent variables and the AVE square root of latent variables is greater than the correlation coefficient between the factor and other factors [8]. 
The correlation coefficient of the latent variable correlation matrix among the discriminant validity results of the confirmatory factor analysis summarized in [Table 4] is highest with $0.677(=0.823 \times 0.823)$ in performance expectation and efforts expectation, and does not exceed the reference value 0.773 between each latent variable. Therefore, it can be said that there is a validity of discrimination between all constructive concepts.

Table 4. Feasibility of Confirmatory Factor Analysis

\begin{tabular}{c|c|c|c|c|c|c|c|c|c|c|c}
\hline & AC & TC & BC & PM & PSec & PI & PSuit & PE & EE & SI & IU \\
\hline AC & 0.773 & & & & & & & & & & \\
\hline TC & 0.417 & 0.871 & & & & & & & & & \\
\hline BC & 0.530 & 0.805 & 0.837 & & & & & & & & \\
\hline PM & 0.521 & 0.483 & 0.605 & 0.787 & & & & & & & \\
\hline PSec & 0.354 & 0.223 & 0.290 & 0.299 & 0.917 & & & & & & \\
\hline PI & 0.448 & 0.460 & 0.502 & 0.331 & 0.336 & 0.819 & & & & & \\
\hline PSuit & 0.599 & 0.661 & 0.755 & 0.502 & 0.446 & 0.616 & 0.848 & & & & \\
\hline PE & 0.499 & 0.796 & 0.774 & 0.537 & 0.385 & 0.529 & 0.793 & 0.854 & & & \\
\hline EE & 0.508 & 0.681 & 0.750 & 0.468 & 0.369 & 0.531 & 0.738 & 0.823 & 0.899 & & \\
\hline SI & 0.602 & 0.469 & 0.562 & 0.469 & 0.403 & 0.569 & 0.630 & 0.593 & 0.561 & 0.861 & \\
\hline IU & 0.603 & 0.605 & 0.668 & 0.433 & 0.430 & 0.665 & 0.791 & 0.721 & 0.684 & 0.786 & 0.913 \\
\hline
\end{tabular}

\subsection{Hypothesis Verification}

Hypothesis tests using system characteristics and parameters showed that the p-values of $\mathrm{H} 2 \mathrm{a}$ and $\mathrm{H} 3 \mathrm{~b}$ were greater than 0.1 and the hypothesis was rejected. All other hypotheses were adopted.

Hypothesis tests using user characteristics and parameters revealed that hypothesis $\mathrm{H} 5 \mathrm{a}$ and $\mathrm{H} 5 \mathrm{~b}$ that individual innovativeness influences performance expectation and effort expectation were all rejected because p-value was greater than 0.1 . All other hypotheses were adopted.

All hypotheses were adopted in hypothesis test results as parameters and dependent variables, and all hypotheses were adopted in hypothesis tests on environmental characteristics and dependent variables.

Table 5. Result of Hypothesis testing with System Characteristics and Parameter

\begin{tabular}{lcccccc}
\hline & Research hypothesis & Estimate & S.E. & C.R. & P & Result \\
\hline $\mathrm{H} 1 \mathrm{a}$ & $\mathrm{TC} \rightarrow \mathrm{PE}$ & 0.267 & 0.066 & 4.019 & $* * *$ & Adopted \\
\hline $\mathrm{H} 2 \mathrm{a}$ & $\mathrm{BC} \rightarrow \mathrm{PE}$ & 0.120 & 0.085 & 1.416 & 0.157 & Rejected \\
\hline $\mathrm{H} 3 \mathrm{a}$ & $\mathrm{PM} \rightarrow \mathrm{PE}$ & 0.059 & 0.030 & 1.985 & 0.047 & Adopted \\
\hline $\mathrm{H} 4 \mathrm{a}$ & $\mathrm{PSec} \rightarrow \mathrm{PE}$ & 0.054 & 0.031 & 1.770 & 0.077 & Adopted \\
\hline $\mathrm{H} 1 \mathrm{~b}$ & $\mathrm{TC} \rightarrow \mathrm{EE}$ & 0.162 & 0.071 & 2.278 & 0.023 & Adopted \\
\hline $\mathrm{H} 2 \mathrm{~b}$ & $\mathrm{BC} \rightarrow \mathrm{EE}$ & 0.215 & 0.091 & 2.363 & 0.018 & Adopted \\
\hline $\mathrm{H} 3 \mathrm{~b}$ & $\mathrm{PM} \rightarrow \mathrm{EE}$ & 0.007 & 0.031 & 0.234 & 0.815 & Rejected \\
\hline $\mathrm{H} 4 \mathrm{~b}$ & $\mathrm{PSec} \rightarrow \mathrm{EE}$ & 0.098 & 0.033 & 2.932 & 0.003 & Adopted \\
\hline
\end{tabular}

TABLE 6. Result of Hypothesis testing with User Characteristics and Parameter

\begin{tabular}{ccccccc}
\hline & Research hypothesis & Estimate & S.E. & C.R. & P & Result \\
\hline H5a & PI $\rightarrow$ PE & 0.007 & 0.052 & 0.132 & 0.895 & Rejected \\
\hline H6a & PSuit $\rightarrow$ PE & 0.458 & 0.073 & 6.255 & $* * *$ & Adopted \\
\hline H5b & PI $\rightarrow$ EE & 0.009 & 0.056 & 0.156 & 0.876 & Rejected \\
\hline H6b & PSuit $\rightarrow$ EE & 0.459 & 0.078 & 5.854 & $* * *$ & Adopted \\
\hline
\end{tabular}


Table 7. Result of Hypothesis Testing with Parameter and Dependent Variable

\begin{tabular}{ccccccc}
\hline & Research hypothesis & Estimate & S.E. & C.R. & P & Result \\
\hline H7 & PE $\rightarrow$ IU & 0.320 & 0.071 & 4.491 & $* * *$ & Adopted \\
\hline H8 & EE $\rightarrow$ IU & 0.191 & 0.065 & 2.951 & 0.003 & Adopted \\
\hline
\end{tabular}

Table 8. Result of Hypothesis Testing with Environmental Characteristics and Dependent Variable

\begin{tabular}{ccccccc}
\hline & Research hypothesis & Estimate & S.E. & C.R. & P & Result \\
\hline H9 & $\mathrm{SI} \rightarrow \mathrm{IU}$ & 0.532 & 0.058 & 9.158 & $* * *$ & Adopted \\
\hline $\mathrm{H} 10$ & $\mathrm{AC} \rightarrow \mathrm{IU}$ & 0.116 & 0.064 & 1.810 & 0.070 & Adopted \\
\hline
\end{tabular}

\subsection{Control Effect Analysis}

This study conducted a control effect analysis in order to understand the difference of use intention of biometric authentication payment upon whether of using of biometric authentication. Among the respondents, there were 112 subjects with experience in biometrics and 141 subjects with no experience.

In addition, this study examined if there is difference in use intention of the biometric authentication payment by age. The respondents were divided into two groups of younger than 39 years old and 40 years old to understand the difference in both groups. Of the respondents, 211 were under 39 years old, and 117 were over 40 years old, and this study performed a multiple group analysis between the two groups to see a significant difference.

Table 9. Result of Use Experience Multi-cluster Analysis

\begin{tabular}{c|c|c}
\hline Division & Non-constrained model & Constrained model \\
\hline $\mathrm{x}^{2}$ & 1543.219 & 1617.985 \\
\hline $\mathrm{X}^{2}$ difference & \multicolumn{2}{|c}{74.767} \\
\hline P-value of $\mathrm{x}^{2}$ difference & \multicolumn{2}{|c}{0.001} \\
\hline
\end{tabular}

The results show that $\mathrm{x}^{2}$ of the non-constrained model is 1543.219 and $\mathrm{x} 2$ of the constraint model (structural weight model) constraining the structural weight (regression coefficient) is 1617.985 . As a result of the $\mathrm{x}^{2}$ difference analysis, the $\mathrm{x}^{2}$ difference is $61.676, \mathrm{p}=0.001$, which is statistically significant [24].

There are many differences in the results of hypothesis testing of biometric authentication payment characteristics variables.

In the group with use experience, transaction convenience, perceived mobility and perceived suitability influence on performance expectations, and transaction convenience, perceived security performance, and perceived suitability influence on the efforts expectations. In the group without use experience, transaction convenience, perceived mobility and perceived suitability influence on performance expectations, and benefits convenience, perceived security, and perceived suitability influence on the efforts expectations. In the hypotheses that influence on the intention to use, both groups showed that performance expectations and social impact influence on the intention to use. 
Table 10. Result of Use Experience Individual Sample Analysis

\begin{tabular}{|c|c|c|c|c|c|c|c|}
\hline \multirow{2}{*}{\multicolumn{2}{|c|}{ Research hypothesis }} & \multicolumn{3}{|c|}{ Use more than once (144) } & \multicolumn{3}{|c|}{ Inexperience in use (184) } \\
\hline & & Estimate & $\mathrm{P}$ & Result & Estimate & $\mathrm{P}$ & Result \\
\hline $\mathrm{TC} \rightarrow$ & \multirow{6}{*}{$\begin{array}{l}\text { Performance } \\
\text { expectation }\end{array}$} & 0.270 & 0.006 & Adopted & 0.182 & 0.055 & Adopted \\
\hline $\mathrm{BC} \rightarrow$ & & 0.034 & 0.713 & Rejected & 0.261 & 0.072 & Adopted \\
\hline $\mathrm{PM} \rightarrow$ & & 0.089 & 0.023 & Adopted & 0.026 & 0.679 & Rejected \\
\hline $\mathrm{PSec} \rightarrow$ & & 0.042 & 0.286 & Rejected & 0.055 & 0.215 & Rejected \\
\hline $\mathrm{PI} \rightarrow$ & & -0.055 & 0.365 & Rejected & 0.031 & 0.657 & Rejected \\
\hline PSuit $\rightarrow$ & & 0.355 & $* * *$ & Adopted & 0.464 & $* * *$ & Adopted \\
\hline $\mathrm{TC} \rightarrow$ & \multirow{6}{*}{ Efforts expectation } & 0.198 & 0.068 & Adopted & 0.033 & 0.738 & Rejected \\
\hline $\mathrm{BC} \rightarrow$ & & 0.017 & 0.868 & Rejected & 0.434 & 0.004 & Adopted \\
\hline $\mathrm{PM} \rightarrow$ & & 0.049 & 0.253 & Rejected & -0.014 & 0.824 & Rejected \\
\hline $\mathrm{PSec} \rightarrow$ & & 0.083 & 0.069 & Adopted & 0.090 & 0.048 & Adopted \\
\hline $\mathrm{PI} \rightarrow$ & & -0.110 & 0.118 & Rejected & 0.060 & 0.406 & Rejected \\
\hline PSuit $\rightarrow$ & & 0.414 & $* * *$ & Adopted & 0.382 & $* * *$ & Adopted \\
\hline $\mathrm{PE} \rightarrow$ & \multirow{4}{*}{ Intention to use } & 0.528 & $* * *$ & Adopted & 0.200 & 0.005 & Adopted \\
\hline $\mathrm{EE} \rightarrow$ & & 0.088 & 0.285 & Rejected & 0.079 & 0.258 & Rejected \\
\hline $\mathrm{SI} \rightarrow$ & & 0.179 & 0.003 & Adopted & 0.598 & $* * *$ & Adopted \\
\hline $\mathrm{AC} \rightarrow$ & & 0.011 & 0.866 & Rejected & 0.124 & 0.140 & Rejected \\
\hline
\end{tabular}

Table 11. Result of Age Multi-Cluster Analysis

\begin{tabular}{c|c|c}
\hline Division & $\begin{array}{c}\text { Non-constrained model } \\
\text { (Unconstrained Model) }\end{array}$ & $\begin{array}{c}\text { Constrained model } \\
\text { (Structural Weights Model) }\end{array}$ \\
\hline $\mathrm{x}^{2}$ & 1558.274 & 1611.061 \\
\hline $\mathrm{X}^{2}$ difference & \multicolumn{2}{|c}{52.787} \\
\hline P-value of $\mathrm{x}^{2}$ difference & \multicolumn{2}{|c}{0.037} \\
\hline
\end{tabular}

The results show that $\mathrm{x}^{2}$ of the constrained model is 1543.219 and $\mathrm{x}^{2}$ of the constrained model (structural weight model) constraining the structural weight (regression coefficient) is 1617.985 . As a result of the $\mathrm{x}^{2}$ difference analysis, the $\mathrm{x}^{2}$ difference is $52.787, \mathrm{p}=$ 0.037, which is statistically significant [13]. Therefore, Hypothesis H12 (there will be a controlling effect on the intention to use the biometric authentication service by age) confirms the significant difference between the two groups, and the difference in hypothesis of each group is analyzed. The results of individual sample analysis are summarized in [Table 12]. Looking into that result, there are many differences in the results of hypothesis testing of biometric authentication payment characteristics variables. The under 39 years old group affects performance expectations, with the exception of benefits convenience and individual innovation, and transactional convenience, perceived security, and perceived suitability influence on efforts expectations. In the group of over 40 years old, transaction convenience and perceived suitability influence on performance expectations, and benefits convenience, perceived security, and perceived suitability influence on the efforts expectations. The group of under 39 years old had an effect on intention to use, and the group of over 40 years old give influence on intention to use, except the activation condition. 
Table 12. Result of Age Individual Sample Analysis

\begin{tabular}{|c|c|c|c|c|c|c|c|}
\hline \multirow{2}{*}{\multicolumn{2}{|c|}{ Research hypothesis }} & \multicolumn{3}{|c|}{$\begin{array}{l}\text { Under } 39 \text { years old } \\
\text { (211 people) }\end{array}$} & \multicolumn{3}{|c|}{$\begin{array}{l}\text { Over } 40 \text { years old } \\
\text { (117 people })\end{array}$} \\
\hline & & Estimate & $\mathrm{P}$ & Result & Estimate & $\mathrm{P}$ & Result \\
\hline $\mathrm{TC} \rightarrow$ & \multirow{6}{*}{$\begin{array}{l}\text { Performance } \\
\text { expectation }\end{array}$} & 0.362 & $* * *$ & Adopted & 0.18 & 0.0046 & Adopted \\
\hline $\mathrm{BC} \rightarrow$ & & 0.094 & 0.423 & Rejected & 0.122 & 0.325 & Rejected \\
\hline $\mathrm{PM} \rightarrow$ & & 0.072 & 0.047 & Adopted & 0.030 & 0.550 & Rejected \\
\hline $\mathrm{PSec} \rightarrow$ & & 0.067 & 0.065 & Adopted & 0.049 & 0.428 & Rejected \\
\hline $\mathrm{PI} \rightarrow$ & & 0.040 & 0.486 & Rejected & -0.212 & 0.175 & Rejected \\
\hline PSuit $\rightarrow$ & & 0.361 & $* * *$ & Adopted & 0.712 & $* * *$ & Adopted \\
\hline $\mathrm{TC} \rightarrow$ & \multirow{6}{*}{$\begin{array}{c}\text { Efforts } \\
\text { expectation }\end{array}$} & 0.207 & 0.043 & Adopted & 0.088 & 0.329 & Rejected \\
\hline $\mathrm{BC} \rightarrow$ & & 0.093 & 0.466 & Rejected & 0.430 & $* * *$ & Adopted \\
\hline $\mathrm{PM} \rightarrow$ & & 0.036 & 0.350 & Rejected & -0.082 & 0.116 & Rejected \\
\hline $\mathrm{PSec} \rightarrow$ & & 0.098 & 0.014 & Adopted & 0.104 & 0.093 & Adopted \\
\hline $\mathrm{PI} \rightarrow$ & & 0.025 & 0.690 & Rejected & -0.090 & 0.541 & Rejected \\
\hline PSuit $\rightarrow$ & & 0.431 & $* * *$ & Adopted & 0.614 & $* * *$ & Adopted \\
\hline $\mathrm{PE} \rightarrow$ & \multirow{4}{*}{$\begin{array}{c}\text { Intention to } \\
\text { use }\end{array}$} & 0.239 & 0.006 & Adopted & 0.419 & $* * *$ & Adopted \\
\hline $\mathrm{EE} \rightarrow$ & & 0.210 & 0.008 & Adopted & 0.234 & 0.041 & Adopted \\
\hline $\mathrm{SI} \rightarrow$ & & 0.529 & $* * *$ & Adopted & 0.495 & $* * *$ & Adopted \\
\hline $\mathrm{AC} \rightarrow$ & & 0.204 & 0.015 & Adopted & 0.011 & 0.924 & Rejected \\
\hline
\end{tabular}

\section{Conclusion}

\subsection{Summary and Implications of Research Results}

The purpose of this study is to summarize biometric authentication services using biometric technology and to examine factors affecting intention to use biometric authentication services. The variables used are based on previous studies and the variables are categorized by system characteristics, user characteristics and environmental characteristics and analyzed and verified the effects of system characteristics and user characteristics on performance expectation and effort expectation, as well as the effects of performance expectation, effort expectation, and environmental characteristics on intention to use. Finally, empirical analysis was conducted to verify the difference in the effect of age and the experience of biometric authentication payment service.

In this study, hypotheses were verified based on 328 questionnaires. As the demographic surveys show, many respondents do not routinely use biometric authentication payment services, so the need for this research is even more emphasized. The following results were derived through hypothesis testing.

First, it has shown that convenience of transaction, perceived security, and perceived suitability have positive effects on performance expectation and effort expectation, respectively. This result is corresponding to the previous study because it feels more convenient than the biometric authentication method provided by the biometric authentication payment service compared to the existing authentication method of the mobile payment system and the mobile banking service, and it is considered as such because the service can be used according to the pattern used familiarly until now.

Second, benefits convenience has a significant effect on effort expectation (ease of use) and perceived mobility has a significant effect on performance expectancy (usefulness). However, benefits convenience has no significant effect on performance expectation (usefulness), and perceived mobility has no significant effect on efforts expectation (ease of use). This is in part consistent with previous studies. The user feels that it is easy to use the biometrics authentication in the financial settlement transaction in terms of time and effort, and it is judged that user feels useful because the service can be used anytime and 
anywhere even on the move. However, in the case of using the biometric authentication payment service, it is judged that the user does not simply feel useful (performance expectation) because of easy and convenient authentication, and does not simply recognize the advantage of availability during the move as the merit of easy use (efforts expectation). Various software and hardware limitations for completing payment services are consequently inconsistent with the ease of use or usefulness. Therefore, as a means to verify identity, expand and apply a simple biometric, and expand infra of self-service to receive payment service anytime and anywhere, and maintain standardization and consistency in user's prospect, by strengthening compatibility so that it is not limited to specific hardware or software that support biometrics authentication payment service, and it is judged that the use will ultimately take its position as a convenient and useful service.

Third, individual innovativeness does not have a positive effect on performance expectation and efforts expectation, and is the result inconsistent with previous research. This is thought to be caused by a vague anxiety or a psychological barrier due to a lack of recognition at the stage when biometrics technology began to be applied. With the advent of the Fourth Industrial Revolution, in the case of constant innovation, if the new innovation service progresses to platform and globalization level, it is considered that the correlation between individual innovativeness is weakened. In biometrics authentication payment service, it is judged that the user does not feel useful or easy as long as there is no guarantee that the payment service is correctly completed due to the nature of the financial transaction of payment. Also, if the issue of information security cannot be dispelled, individual innovation will have the same results. If various biometric technologies are applied and biometrics authentication payment service is expanded in the future, it will have a positive effect on performance expectation and efforts expectation.

Finally, performance expectations and effort expectations, like the results from traditional TAM and UTAUT-based studies, have positive effects on intention to use, respectively. It is consistent with the results of previous studies that users think that usefulness or ease of use of biometrics authentication payment service has a positive effect on intention to use.

\subsection{Limitations of Research and Future Research Tasks}

This study examines the factors that influence on the intention to use biometrics authentication payment service and has several limitations. This should be supplemented by continuous research in the future.

First, this study set the variables based on the previous studies of technology-based self-service having non-face-to-face offline characteristics and mobile payment system that has online technology and validated the factors affecting on the intention to use biometrics authentication payment service. Currently, biometrics authentication payment service is mainly used for simple payment, but it is expected to become more various types of services in the future. Therefore, it is possible to derive more meaningful verification results by using the methodology that can identify the unique variables affecting on biometrics authentication payment service.

Second, since biometrics is mostly used for fingerprint recognition, experience of using various biometric information is lacking, and biometric authentication payment is not yet provided in various areas and forms, this study also cannot help verifying in very limited service. If a variety of biometric authentication and service areas are expanded in the future, it would be more meaningful to conduct research on the intention to use by dividing into the kind of biometrics and payment service area. 


\section{References}

[1] A. İsmet, "Technology-based self-service: From customer Productivity toward customer value”, Ph.D dissertation, University of Tennessee, (2005).

[2] B. K. Sun and J. Ha, "A Secure and Lightweight Mobile Payment Protocol Based on Smartcard", Journal of Security Engineering, vol. 12, no. 3, (2015), pp. 259-272.

[3] C. Yang and M. H. Kim, "A Study on individual, technical and social characteristics on Acceptance Intention of the Mobile Payment Application", Asia-pacific Journal of Multimedia Services Convergent with Art, Humanities, and Sociology, vol. 7, no. 1, (2017), pp. 45-59.

[4] J. M. Curran, M. L. Meuter and C. F. Surprenant, "Intentions to use self-service technologies: a confluence of multiple attitudes", Journal of Service Research, vol. 5, no. 3, (2003), pp. 209-224.

[5] P. A. Dabholkar and R. P. Bagozzi, "An attitudinal model of technology-based self-service: moderating Effects of consumer traits and situational factors", Journal of the Academy of Marketing Science, vol. 30, no. 3, (2002), pp. 184-201.

[6] P. A. Dabholkar, "Consumer evaluations of new technology-based self-service options: An investigation of alternative models of service quality", International Journal of Research in Marketing, vol. 13, no. 1, (1996), pp. 29-51.

[7] DMC Media, "Understanding and Prospect of Mobile Easy Payment Service", (2015).

[8] C. Fornell and D. F. Larcker, "Evaluating structural equation models with unobservable variables and measurement error", Journal of Marketing Research, vol. 18, no. 1, (1981), pp. 39-50.

[9] D. Gefen, D. Straub and M. C. Boudreau, "Structural equation modeling and regression: Guidelines for research practice", Communications of Association Information Systems, vol. 4, no. 7, (2000), pp. 1-77.

[10] H. Yan and Z. Yang, "Examining Mobile Payment User Adoption from the Perspective of Trust", International Journal of u- and e-Service, Science and Technology, vol. 8, no. 1, (2015), pp. 117-130.

[11] J. Li, J. L. Liu and H. Y. Ji, "Empirical Study of Influence Factors of Adaption Intention of Mobile Payment based on TAM Model in China", International Journal of $u$ - and e-Service, Science and Technology, vol. 7, no. 1, (2014), pp. 119-132.

[12] J. H. Jung and Y. G. Jung, "A proposal for the non-face-to-face real name confirmation trends and securing safety at home and abroad", KFTC, Payment settlement and information technology, no. 64, (2016).

[13] J. H. Jung, G. Kim and J. J. Lee, "A Study on the Factors Affecting on User Satisfaction and Persistent Intention of Mobile Credit Card", Journal of the Korean Institute of Electronic Transaction, vol. 20, no. 3, (2015), pp. 11-28.

[14] G. S. Kim, “AMOS 18.0 Structural Equation Model Analysis”, Hannarae Academy, (2010).

[15] J. H. Kim, "Software and Internet content: Electronic payment system", Information Industry Trend, (2002), pp. 56-73.

[16] S. Y. Kim, "A Study on the Factors Affecting the Intention to Use Biometrics in Payment Services", $\mathrm{Ph} . \mathrm{D}$ dissertation, Soongsil University, (2017).

[17] B. Kim, I. Han, "What drives the adoption of mobile data services? An approach from a value perspective", Journal of Information Technology, vol. 24, no. 1, (2009), pp. 35-45.

[18] H. Y. Lee, "Data analysis using Professor Lee Hoonyoung's SPSS (2nd edition)", Cheongram, (2013).

[19] J. D. Lee, "Applying Status and Development Tasks of Financial Services in Biometrics Technology", KFTC, Payment settlement and information technology, no. 57, (2014).

[20] P. Luarn and H. H. Lin, "Toward an understanding of the behavioral intention to use mobile banking", Computers in Human Behavior, vol. 21, no. 6, (2005), pp. 873-891.

[21] G. L. Marzocchi, and A. Zammit, "Self-scanning technologies in retail: Determinants of adoption", The Service Industries Journal, vol. 26, no. 6, (2006), pp. 651-669.

[22] M. Soltane, N. Doghmane, N. Guersi, "Face and Speech Based Multi-Modal Biometric Authentication", International Journal of Advanced Science and Technology, vol. 21, (2010), pp. 41-56.

[23] T. T. T. Pham and J. C. Ho, "The effects of product-related, personal-related factors and attractiveness of alternatives on consumer adoption of NFC-based mobile payments", Technology in Society, vol. 43, (2015), pp. 159-172.

[24] G. W. Shin, "Following AMOS 20 Statistical Analysis", Cheongram, (2013).

[25] S. Taylor and P. A. Todd, "Understanding information technology usage: a test of competing models", Information Systems Research, vol. 6, no. 2, (1995), pp. 144-176.

[26] A. J. Tomarken and N. G. Waller, "Potential problems with "Well Fitting" models", Journal of Abnormal Psychology, vol. 112, no. 4, (2003), pp. 578-598.

[27] V. Venkatesh, M. G. Morris, G. B. Davis, F. D. Davis, W. H. DeLone, E. R. McLean and B. L. Marcolin, "User acceptance of information technology: Toward a unified view", MIS Quarterly, vol. 27, no. 3, (2003), pp. 425-478.

[28] S. Yang, Y. Lu, S. Gupta, Y. Cao and R. Zhang, "Mobile payment services adoption across time: An empirical study of the effects of behavioral beliefs, social influences, and personal traits", Computers in Human Behavior, vol. 28, no. 1, (2012), pp. 129-142. 